\title{
VIGILANCIA DE LA SALUD, DERECHO A LA INTIMIDAD Y COVID-19
}

\author{
Health surveillance, right to privacy and covid-19 \\ Raquel Poquet Catala* \\ Universidad de Valencia, España
}

\section{RESUMEN}

En este trabajo se plantea, a la luz de la situación que estamos viviendo con la pandemia declarada por la OMS el pasado 11 de marzo de 2020, ocasionada por el COVID-19, una serie de aspectos relacionados con la vigilancia de la salud y el derecho a la intimidad de la persona trabajadora. Concretamente, se trata de ver cuál es la capacidad de las empresas para obligar a las personas trabajadoras a someterse a un reconocimiento médico con el fin de determinar su estado de salud en relación con el COVID-19, o la posibilidad de que las empresas lleven a cabo prácticas consistentes en realizar un reconocimiento médico con carácter previo a la contratación, o solicitar a las personas candidatas a un puesto de trabajo información sobre si han pasado el COVID-19.

Palabras clave: vigilancia de la salud, reconocimiento médico, COVID-19, intimidad, datos de carácter personal.

\section{ABSTRACT}

In this work it is analyzed, in light of the situation we are experiencing with the pandemic declared by the WHO on March 11th 2020, caused by COVID-19, a series of aspects related to health surveillance and right to privacy of the worker. Specifically, it is studied if the companies can compel workers to undergo a medical examination in order to determine their health status in relation to COVID-19, or the possibility that companies carry out practices consisting of doing a medical examination prior to hiring, or requesting candidates for a job information on whether they have passed COVID-19.

Keywords: health surveillance, medical examination, COVID-19, privacy, personal data.

\footnotetext{
* Correspondencia a: Raquel Poquet Catala. Passeig De Les Germanies, 104, 5-9, 46702, Gandia, (Valencia), España. - raquel.poquet@uv.es - https://orcid.org/0000-0001-9606-8832

Cómo citar: Poquet Catala, Raquel. (2020). «Vigilancia de la salud, derecho a la intimidad y Covid-19»; Lan Harremanak, 44, 15-38. (https://doi.org/10.1387/lan-harremanak.21901).

Recibido: 07 julio, 2020; aceptado: 04 noviembre, 2020.

ISSN 1575-7048 - elSSN 2444-5819 / (C) 2020 UPV/EHU
} 


\section{Introducción}

Como es sabido, el art. 22 LPRL establece la obligación de la empresa de garantizar la salud de las personas trabajadoras a su servicio, estableciendo una vigilancia periódica de su estado de salud en función de los riesgos inherentes al trabajo. Tanto al inicio como durante la prestación de servicios la persona trabajadora tiene reconocido el derecho a la vigilancia de la salud, que es concreción del genérico derecho de las personas trabajadoras a una protección eficaz en materia de seguridad y salud en el trabajo que les reconoce el art. 14 LPRL, lo que hace surgir el correlativo deber empresarial en virtud de la deuda de seguridad que tiene contraída con aquéllos. En este sentido, y haciendo trasposición de lo dispuesto en el art. 14 Directiva Marco 1989/391, la LPRL, en su art. 22, se expresa en los términos siguientes: «El empresario garantizará a los trabajadores a su servicio la vigilancia periódica de su estado de salud en función de los riesgos inherentes al trabajo».

Por otro lado, con la situación ocasionada con la crisis sanitaria con motivo de la pandemia por el COVID-19 declarada por la OMS el pasado 11 de marzo de 2020, el estado de salud se ha vuelto en un elemento clave en todo ámbito y, especialmente, en el laboral.

En este sentido, y teniendo presente que no es el derecho a la vida y a la integridad física el único derecho afectado y a preservar en el momento de hacer un tratamiento de la vigilancia de la salud de las personas trabajadoras, sino que existen otros derechos fundamentales como es el caso de la dignidad, la libertad e intimidad de la persona o la no discriminación, quedan por definir unas zonas grises importantes. De ahí que en la Exposición de Motivos de la LPRL se subraye que en la vigilancia de la salud de las personas trabajadoras se prestará especial «atención a la protección de la confidencialidad y el respeto a la intimidad en el tratamiento de estas actuaciones»; el art. 22.2 de la misma Ley se refiere a que la vigilancia y control de la salud de los trabajadores encuentra un límite en el respeto al derecho a la intimidad y a la dignidad de la persona del trabajador y la confidencialidad de toda información relacionada con su estado de salud». Es más, la puesta en práctica del control de la salud del trabajador, es decir, los datos personales sanitarios podrían ser utilizados en su perjuicio o con fines discriminatorios, razón por la cual se impone la prohibición de tal uso y se trata de garantizar la confidencialidad de toda información relacionada con su estado de salud (art. 22.4 LPRL). De hecho, el TC ${ }^{1}$ ha declarado que el art. 18.1 CE dispensa una protección que alcanza a la intimidad corporal y que ésta forma parte del derecho a la intimidad personal.

\footnotetext{
${ }^{1}$ Entre otras, SSTC 207/1996, de 16 de diciembre; 234/1997, de 18 de diciembre; y 196/2004, de 15 de noviembre.
} 
Podemos sintetizar los siguientes puntos de fricción entre la dignidad e intimidad de la persona trabajadora y los reconocimientos médicos. Por un lado, cuando dichos reconocimientos carezcan de finalidad preventiva, obedeciendo a otros propósitos empresariales, sean o no lícitos, que queden enmascarados por una apariencia de legitimidad y bajo su poder de dirección. Y, por otro lado, cuando, aun teniendo finalidad preventiva, la realización de dichos reconocimientos produzca un menoscabo injustificado en la intimidad y dignidad del trabajador, como es el caso del sometimiento a los reconocimientos médicos en los supuestos obligatorios para el trabajador, o cuando las pruebas clínicas practicadas no resulten proporcionadas o mediante las mismas se obtengan datos innecesarios sobre la persona del trabajador o su vida privada, o incluso cuando los datos o informaciones obtenidas como consecuencia de los reconocimientos médicos sean utilizados de manera indebida y/o sin respetar la confidencialidad de los mismos.

En este sentido se han planteado diversos conflictos con relación a la vigilancia de la salud y la situación de crisis sanitaria ocasionada por el COVID-19. Así, se ha cuestionado si las empresas pueden obligar a las personas trabajadoras a someterse a un reconocimiento médico con tal fin; si pueden obligar a las personas trabajadoras a someterse a un reconocimiento médico previo con el fin de detectar una posible inmunidad frente a la citada enfermedad; o si las empresas pueden solicitar a las personas candidatas a un puesto de trabajo información sobre si han pasado el COVID-19.

\section{Covid-19 y obligatoriedad del reconocimiento médico}

Tal y como se desprende del art. 22 LPRL, la voluntariedad es la regla general en la realización de los reconocimientos médicos por parte de las personas trabajadoras, siendo únicamente obligatorios en tres supuestos excepcionales, pero de cuya literalidad normativa se desprenden diversas dudas. En este sentido, y en relación con la situación de crisis sanitaria ocasionada por el virus SARS-COV-2, se ha planteado si la empresa puede obligar a un trabajador a someterse a un reconocimiento médico.

En principio debe entenderse que, tal y como indica el art. 22.1 LPRL, la vigilancia sólo podrá llevarse a cabo "cuando el trabajador preste su consentimiento", de tal forma que la persona trabajadora es libre para decidir someterse o no a los controles médicos. En otras palabras, la regulación legal significa, en principio, que la empresa debe proponer los reconocimientos médicos, pudiendo la persona trabajadora aceptar o rehusar su práctica ${ }^{2}$. No obstante, como

2 STS de 28 de noviembre de 2006, rec. núm. 140/2005. 
a continuación se analizará, las excepciones a la voluntariedad por parte de la persona trabajadora son de tal amplitud, que desde un primer momento la doctrina científica se cuestionó hasta qué punto la voluntariedad constituye la regla y la obligatoriedad la excepción (Blasco Pellicer, 1999:107). Así, el TC ${ }^{3}$ ha rechazado una utilización extensiva de estas habilitaciones legales $y$, por ende, que las situaciones excepcionales se hagan mayoritarias, pues se desfigura la regla ordinaria de libertad de decisión de la persona trabajadora cuando se den determinadas notas, como la proporcionalidad del riesgo, la inexistencia de las opciones alternativas de menor impacto en el núcleo de los derechos individuales, la indispensabilidad de las pruebas, por acreditarse ad cassum la necesidad objetiva de su realización en atención al riesgo que se procura prevenir, así como los motivos que llevan al empresario a realizar la exploración médica a un trabajador singularmente considerado, y la presencia de un interés preponderante del grupo social o de la colectividad laboral o una situación de necesidad objetivable, descrita en los supuestos del art. 22.1.2 LPRL. Los límites legales quedan vinculados, o bien a la certeza de un riesgo o peligro en la salud de las personas trabajadoras o terceros, o bien, en determinados sectores, a la protección frente a riesgos específicos y actividades de especial peligrosidad. La obligatoriedad no puede imponerse, en cambio, si únicamente está en juego la salud del propio trabajador, sin el ańadido de un riesgo o peligro objetivable, pues aquél es libre de disponer de la vigilancia de su salud sometiéndose o no a los reconocimientos en atención a las circunstancias y valoraciones que estime pertinentes para la decisión. De hecho, nuestro alto tribunal ${ }^{4}$ tiene declarado que la interpretación del alcance que poseen las tres excepciones a la regla de la voluntariedad no puede prescindir de los criterios sentados por el TC.

Estos criterios se resumen en los siguientes: 1. La determinación de una vigilancia periódica del estado de salud de las personas trabajadoras en función de los riesgos inherentes a su actividad laboral. 2. La voluntariedad del sometimiento a los reconocimientos médicos. 3. La existencia de situaciones tasadas en las que resulta imprescindible la realización de las exploraciones médicas, limitándose así, excepcionalmente en esos casos, la libre determinación del sujeto. 4. El principio de la indispensabilidad de las pruebas y de su proporcionalidad al riesgo. 5. El necesario respeto del derecho a la intimidad, a la dignidad de la persona y a la confidencialidad de la información relacionada con su estado de salud. 6. El derecho de la persona trabajadora a conocer los resultados; la prohibición de utilización de los datos relativos a la vigilancia de la salud con fines discriminatorios o en perjuicio del trabajador. 7. La prohibición de comunicación de la información resultante, salvo que exista consentimiento expreso del trabajador. 8. La posibilidad de transmitir al empresario y a las personas u órga-

\footnotetext{
3 STC 196/2004, de 15 de noviembre.

4 STS de 10 de junio de 2015, rec. núm. 178/2014.
} 
nos con responsabilidades en materia de prevención únicamente las conclusiones que se deriven de las exploraciones y con el exclusivo objeto de que puedan desarrollar sus funciones en materia preventiva (García-Perrote Escartín, Mercader Uguina, 2017).

Ello supone pues que:

el derecho del trabajador a preservar su intimidad personal cede así ante el derecho a la salud del resto de trabajadores que puedan verse afectados por el estado patológico de un compañero y el de la empresa a conocer la existencia de enfermedades capaces de originar riesgos ańadidos al puesto de trabajo y situaciones de peligro para cuantos se relacionan con el trabajador enfermo, circunstancia en virtud de la cual se establecen tres excepciones a la regla general de voluntariedad 5 .

\subsection{Primera excepción}

El primer supuesto en que el reconocimiento médico viene establecido con carácter obligatorio se refiere a aquellos casos en que «sea imprescindible para evaluar los efectos de las condiciones de trabajo sobre la salud de los trabajadores». La obligatoriedad está suficientemente fundada, pues sólo conociendo cómo inciden las distintas condiciones de trabajo, la empresa puede cumplir con los distintos deberes que sobre él hace recaer la ley (Sala Franco, Arnau Navarro, 1996: 23), pero que, si se tiene en cuenta que el principal propósito de la vigilancia de la salud es comprender mejor el impacto que el trabajo tiene sobre la salud de las personas trabajadoras, puede provocar la tentación de considerar que todo reconocimiento es imprescindible. Por ello, esta causa tiene que entenderse, necesariamente, en sentido restrictivo, sólo cuando sea inevitable, esto es, cuando no haya otro procedimiento alternativo para evaluar los riesgos que afecten la salud del trabajador (García Blasco, González Labrada, 1998: 211). Si lo hay, habrá que utilizarlo antes que el reconocimiento (Cavas Martínez, 2004). Una exigencia que no es sino la traslación al ámbito de la vigilancia de la salud de la doctrina del TC sobre el juicio de proporcionalidad y de justificación de la medida, de manera que no basta con la afirmación del interés empresarial, sino que tales exigencias organizativas deberán venir especialmente cualificadas por razones de necesidad siendo preciso acreditar que la restricción del derecho de la persona trabajadora es el único medio razonable para el logro del legítimo interés empresarial ${ }^{6}$.

De hecho, un sector doctrinal (Goñi Sein, 1999: 69) pone el acento en la excesiva regulación que hace el legislador, cuando en la actualidad la mayoría de las patologías laborales son genéricas e inespecíficas, y reciben tratamiento epi-

\footnotetext{
5 STS de 10 de junio de 2015, rec. núm. 178/2014.

6 SSTC 99/1994, de 11 de abril; 136/1996, de 23 de julio.
} 
demiológico adecuado, determinándose el origen, la frecuencia y distribución de los problemas de salud, de manera que en este supuesto no estaría justificado el recurso al interés colectivo sobre el interés individual del trabajador. Se señala que, tal vez, la única causa que justifique los reconocimientos médicos para evaluar los efectos sobre la salud de la persona trabajadora de las condiciones de trabajo sea identificar patologías o condiciones de salud incompatibles con el trabajo.

Por su parte, la doctrina judicial considera que el término «imprescindible» conlleva que no basta la mera conveniencia y que el reconocimiento debe ser inevitable, es decir, que no haya otro procedimiento alternativo para evaluar los riesgos que afectan a la salud del trabajador, de tal forma que cuando una empresa decide someter a todas las personas trabajadoras que se reincorporan tras una baja laboral prolongada a reconocimiento médico, si no existen datos probados concretos de significado contrario, no hay

razón específica para calificarla de imprescindible, ya que ha de presumirse que el alta médica recibida responde a una valoración especializada sobre la recuperación por el trabajador de su capacidad laboral en condiciones que le permiten afrontar con seguridad para sí, sus compañeros de trabajo y terceros los requerimientos físicos-psíquicos del puesto de trabajo ${ }^{7}$.

En esta primera excepción no encajaría la obligatoriedad de llevar a cabo el reconocimiento médico a las personas trabajadoras para detectar la sintomatología compatible con COVID-19, pues en esta salvedad se pretende comprobar cómo el trabajo afecta a la salud de la persona trabajadora, y lo que se trata es más bien de evitar que la persona trabajadora que esté infectada pueda contagiar a otras personas trabajadoras, e incluso terceras personas.

\subsection{Segunda excepción}

El segundo supuesto a la regla general de la voluntariedad viene establecido para aquellos casos en que sea necesario "para verificar si el estado de salud del trabajador puede constituir un peligro para el mismo, para los demás trabajadores o para otras personas relacionadas con la empresa». Como se observa, cabe diferenciar, por un lado, la obligación como manifestación de la protección de la persona individualmente considerada, y, por otro lado, la derivada de la consideración de la prevención como control de los riesgos en el trabajo, en la medida en que la persona trabajadora constituye el «riesgo». Es decir, en la medida en que se considera el estado biológico de la persona trabajadora un riesgo para la salud pública se le impone obligatoriamente el sometimiento a los reconocimientos médicos que sean precisos (Martínez Fons, 2003: 54).

7 STSJ Asturias, de 9 de noviembre de 2007, rec. núm. 2651/2007. 
Por un lado, esto es, cuando se pretende asegurar la tutela de la persona trabajadora frente a los riesgos que puedan derivar de su estado de salud, las medidas de vigilancia parecen referirse al estado de salud en relación con el desarrollo de la prestación, las condiciones ambientales o de organización que pudieran afectar a la persona trabajadora. Esta previsión debe ponerse en relación con los supuestos comprendidos en el art. 25.1 LPRL, esto es, las personas trabajadoras que, a causa de sus características personales, estado biológico o por su discapacidad física, psíquica o sensorial debidamente reconocida puedan ellos, las demás personas trabajadoras $\mathrm{u}$ otras personas relacionadas con la empresa ponerse en situación de peligro. Ambas previsiones están inspiradas en la existencia de un riesgo en la salud por las características personales, anatómicas o biológicas del sujeto, por lo que la potencial afectación a la intimidad de la persona trabajadora, de tener que someterse conforme a la Ley, en su caso, a pruebas y controles médicos como condición para el acceso o el mantenimiento del puesto de trabajo, sólo podrá encontrar fundamento en la evaluación o identificación de tales patologías o condiciones de salud contraindicadas para el trabajo. Es así que la doctrina judicial ${ }^{8}$ ha considerado que puede concurrir tal circunstancia de riesgo cuando en razón de las máquinas que maneja la persona trabajadora su estado de salud constituye un riesgo para el resto de personas trabajadoras. De otro modo, esta excepción carecería de autonomía propia hasta constituirse en una reiteración del primer supuesto excepcional. Se constituye así en una medida de tutela especial de las personas trabajadoras cuyo estado de salud puede resultar un riesgo cierto en la realización de la prestación de trabajo e instrumento cualificado de la tutela de las personas trabajadoras sensibles en la definición del art. 25 LPRL. Es de conformidad con ello que debe ser interpretada la alusión al "peligro" que represente el estado de salud para la persona trabajadora, de manera que la obligatoriedad únicamente estará justificada en aquellos casos en los que el eventual riesgo presente, en función de la actividad que desarrolla la persona trabajadora, realidad y entidad suficiente para considerar necesaria la adopción de medidas preventivas o de protección, entre las cuales se halla el cambio de puesto de trabajo (Lousada Arochena, 1997: 559).

De esta forma, puede diferenciase entre ambos supuestos un distinto fundamento y naturaleza. Así, cuando la salud implica un riesgo para la salud de las personas trabajadoras la medida de reconocimiento médico no es sino expresión del deber de protección que recae sobre la empresa, con la única especialidad que en tal caso el riesgo no proviene de factores inherentes a la actividad de producción de la empresa, sino de alguno o algunos de las personas trabajadoras, mientras que cuando la persona trabajadora comporta un riesgo para terceros nos hallamos ante la imposición de una obligación de carácter público en defensa de la salud pública.

8 STSJ Castilla y León, de 3 de diciembre de 1996, rec. núm. 1111/1996. 
Por ello, la obligatoriedad de medidas de vigilancia de la salud sobre la persona cuando ésta represente un riesgo para otras personas trabajadoras de la empresa requiere tomar en consideración diversos factores, tales como el estado de salud de la persona trabajadora, esto es, la gravedad de la dolencia, así como la facilidad de que la dolencia se convierta en un riesgo cierto para el resto de personas trabajadoras; la prestación que desarrolla la persona trabajadora, en cuanto factor que puede proyectar el riesgo sobre las personas trabajadoras de la empresa; y las condiciones de trabajo, en la medida en que constituyan factor de atenuación o amplificación del inicial riesgo que representa la salud de la persona trabajadora. Resulta evidente, por tanto, que la actividad preventiva no exige esperar a que el peligro para la propia persona trabajadora o el de otras personas con ella relacionadas por motivos de su puesto de trabajo se concrete en un daño o lesión real para adoptar una medida, pues es precisamente el daño lo que se pretende evitar?.

Cuando el estado de salud de la persona trabajadora representa un peligro no sólo para las otras personas trabajadoras, sino para terceros ajenos a la empresa, atendiendo a la dimensión pública que presenta en tal caso la obligación, cabe plantearse hasta qué punto no corresponde al poder público el establecimiento de tales supuestos con carácter general. En una primera aproximación, la obligación de sometimiento a las medidas de vigilancia médica en tales supuestos resultaría congruente con el juego de la responsabilidad derivada de los eventuales dańos que tuvieran su origen en el estado de salud de la persona trabajadora. Y ello porque, como es sabido, ex art. 1903 CC, la empresa debe responder, en todo caso, por los dańos causados por sus empleados. Ahora bien, por un lado, tal conclusión únicamente cabe sostenerla si se admite que el cumplimiento de la obligación de hacer de la empresa le libera de cualquier responsabilidad frente a terceros, cosa que no resulta ajustada a la responsabilidad del art. 1903 CC. Consiguientemente, en razón del carácter esencialmente público que presenta la imposición de medidas destinadas a vigilar la salud en tales casos, la adopción de medidas de vigilancia de la salud debería reducirse exclusivamente a los supuestos en los que se convenga que el contenido mismo de la prestación del trabajador, objetivamente contemplado y tomando en consideración su tratamiento jurídico-público, pueda afectar a la salud pública, al integrar canales aptos para la transmisión de enfermedades que permitan concluir la existencia de un riesgo grave. En tales casos, las limitaciones que representa la necesaria salvaguarda de la salud pública se extienden asimismo a los daños sobre la salud derivados de las personas que prestan servicios por su cuenta (Martínez Fons, 2003: 60).

Por otro lado, si bien la necesidad de evitar dańos a otras personas o a las demás personas trabajadoras es justificación suficiente para exigir el carácter obli-

9 STSJ Andalucía, de 1 de julio de 1998, rec. núm. 4515/1997. 
gatorio del reconocimiento, cuando lo que está en juego es la salud de la propia persona trabajadora la cuestión es menos clara, hasta el extremo de que parte de la doctrina (González Ortega, Aparicio Tovar, 1996: 95) ha defendido que el reconocimiento debería ser en todo caso voluntario, en la consideración de que lo que se reconoce a la persona trabajadora es un derecho a la vigilancia de la salud y no un deber de estar sano y que puede ser que existan otros intereses personales que la persona está interesada en proteger. No obstante, ha de tenerse en cuenta que la empresa no debe emplear a una persona trabajadora cuyas condiciones psicofísicas no sean las adecuadas para el puesto de trabajo y determinen un peligro para la propia persona trabajadora y que puede resultar responsable si efectivamente ese riesgo que amenaza a la persona trabajadora se materializa, por lo que parece razonable la exigencia de tales reconocimientos (Sala Franco, Arnau Navarro, 1996: 23; Purcalla Bonilla, 1997), sin perjuicio de que, la obligatoriedad no podrá imponerse si únicamente está en juego la salud de la propia persona trabajadora, sin el añadido de un riesgo o peligro de cierta gravedad y cierto, porque existan razones fundadas para sospechar de su existencia, so riesgo, en caso contrario, de vaciar de contenido el derecho de la persona a negarse a someterse a aquellas pruebas. Un ejemplo típico es el de los conductores, por la evidente peligrosidad y riesgo para personas y medios que la tarea de conducción y maquinaria entraña ${ }^{10}$ o los miembros de las brigadas de prevención y extinción de incendios ${ }^{11}$.

Es en esta segunda excepción donde se puede plantear la problemática de si una empresa puede exigir o no a su plantilla que sea dada de alta tras el COVID-19 que debe someterse a un reconocimiento médico. Según una línea judicial $^{12}$ debe mantenerse una postura restrictiva, pues:

la disposición adoptada por la empresa demandada de someter a todos los trabajadores tras una baja laboral prolongada a un reconocimiento médico, podrá o no ser considerada una medida conveniente, pero en el caso del actor, ante la falta de datos probados concretos de significado contrario, no hay razón específica alguna para calificarla de imprescindible, ya que ha de presumirse que el alta médica recibida responde a una valoración especializada sobre la recuperación por la persona trabajadora de su capacidad laboral en condiciones que le permitan afrontar con seguridad para sí, sus compańeros de trabajo y terceros los requerimientos físicospsíquicos del puesto de trabajo. La aplicación por la empresa de pautas generales de actuación del tipo de la examinada debe estar justificada, esto es, debe demostrarse su ajuste a los parámetros legales, caso por caso y con rigor, sin apelaciones genéricas a la prevención de riesgos laborales, sino con exposición y prueba de los ele-

10 STSJ Andalucía, de 19 de julio de 2018, rec. núm. 3101/2017. En sentido similar, STS de 21 de enero de 2019, rec. núm. 4009/2016; STSJ Cataluña, de 31 de marzo de 2016, rec. núm. 304/2016, en relación con un conductor de máquina de barrido mecánico.

11 STS de 10 de junio de 2015, rec. núm. 178/2014.

12 STSJ Asturias, de 9 de noviembre de 2007, rec. núm. 2651/2007. 
mentos de hecho demostrativos de que la medida es imprescindible; en otro caso la empresa tendría en su mano una capacidad prácticamente ilimitada para ejercer un control férreo sobre los trabajadores, que hoy por hoy no está permitido, salvo en supuestos singulares.

No obstante, según la posición del Comité europeo de Protección de Datos, en declaración de 19 de marzo de 2020, en la que se marcan las líneas esenciales a tener en cuenta en el tratamiento de datos de salud derivados del control de la pandemia en las empresas, defiende la tesis de que la situación de emergencia es una condición legal que puede legitimar ciertas restricciones de las libertas, siempre que, lógicamente, sean proporcionadas y limitadas. En el mismo sentido, la AEPD considera que:

verificar si el estado de salud de las personas trabajadoras puede constituir un peligro para ellas mismas, para el resto del personal, o para otras personas relacionadas con la empresa constituye una medida relacionada con la vigilancia de la salud de los trabajadores que, conforme a la Ley de prevención de Riesgos Laborales, resulta obligatoria para el empleador ${ }^{13}$.

En este sentido, la necesidad de realizar estos reconocimientos médicos se presenta como una medida tendente a reducir el riesgo de transmisión del COVID-19 en los centros de trabajo, y este presupuesto es la causa que justifica la práctica de estos controles entre la plantilla de una empresa. De hecho, el propio Ministerio de Sanidad ha reconocido la importancia que la detección precoz de la infección tiene en la lucha contra la pandemia, haciendo especial referencia a la importancia que los servicios de prevención de las empresas tienen en esta detección, pues «están llamados a colaborar con las autoridades sanitarias en la detección precoz de todos los casos compatibles con COVID-19 para controlar la trasmisión» (Ministerio de Sanidad, 2020:3).

No cabe duda de que, en el contexto actual de crisis sanitaria, y con la finalidad de evitar la propagación del coronavirus SARS-CoV-2, y ya no sólo en el ámbito laboral, sino en toda la sociedad en general, queda justificada la obligatoriedad de realizar estos reconocimientos médicos por la peligrosidad que puede suponer el estado de salud de una persona trabajadora, tanto para él, como para el resto de personas trabajadoras, y la sociedad en general.

En el momento que estamos viviendo, la dimensión de la protección de la vida y la integridad física de los ciudadanos del art. 15 así como del art. 43.1 $\mathrm{CE}$, adquiere un cariz importante y suficientemente justificativo para legitimar estos reconocimientos médicos con carácter obligatorio.

13 Disponible en https://sedeagpd.gob.es/sede-electronica-web/vistas/infoSede/detallePreguntaFAQ.jsf?idPregunta=FAQ\%2F00293 
Además, no se trata sólo del derecho a la salud y seguridad laboral, sino que entra en juego también el derecho a la salud pública del art. 3 LO 3/1986, de 14 de abril, de medidas especiales en materia de salud pública que establece que, con el fin de controlar las enfermedades trasmisibles, la autoridad sanitaria, puede adoptar las medidas oportunas para el control de los enfermos o las personas que estén o hayan estado en contacto con los mismos.

Debe indicarse asimismo que en el Procedimiento de actuación para los servicios de prevención de riesgos laborales frente a la exposición al SARS-CoV-214, el Ministerio de Sanidad establece que corresponde a las empresas evaluar el riesgo de exposición en que se pueden encontrar las personas trabajadoras. La empresa debe seguir las recomendaciones del servicio de prevención, siguiendo las pautas de las autoridades sanitarias.

$\mathrm{Y}$ en el caso de que las indicaciones de las autoridades sanitarias fuesen insuficientes, el servicio de prevención será quien, según el art. 31 LPRL, tome las decisiones en materia de evaluación de riesgos que puedan afectar a la seguridad y salud laboral de las personas trabajadoras; planificación de la actividad preventiva; determinación de las prioridades en la adopción de medidas preventivas; y vigilancia de la salud de las personas trabajadoras.

Por tanto, el servicio de prevención, por delegación del Ministerio de Sanidad, es quien deberá adoptar unas medidas preventivas y de vigilancia de la salud que estime adecuadas, como podría ser la necesidad de aplicar un control de la temperatura de las personas trabajadoras en una empresa, o la necesidad de realizar reconocimientos médicos o pruebas de PCR.

De esta forma, en virtud del art. $20 \mathrm{ET}$, que permite a la empresa que pueda adoptar medidas de vigilancia y control que estime oportunas, la empresa podría establecer esta necesidad de realizar un reconocimiento médico o prueba PCR.

\subsection{Tercera excepción}

En tercer lugar, el reconocimiento médico tampoco será potestativo para la persona trabajadora "cuando así esté establecido en una disposición legal en relación con la protección de riesgos específicos y actividades de especial peligrosidad». Esta expresión de la «disposición legal» es la que ha desatado, entre otras, una importante controversia doctrinal sobre su alcance. Un sector (González Ortega, Aparicio Tovar, 1996: 97) estima que existe una exigencia de rango formal, como el art. 243 LGSS, según el cual las empresas que pretendan cubrir puestos de trabajo con riesgo de enfermedades profesionales están obligadas a practicar un reconocimiento previo a la contratación de las personas trabajadoras que hayan de ocupar-

14 Disponible en https:/www.mscbs.gob.es/profesionales/saludPublica/ccayes/alertasActual/ nCov/documentos/Proteccion_Trabajadores_SARS-CoV-2.pdf 
los y no podrán contratar a quienes en el reconocimiento médico obligatorio no hayan sido calificados como aptos para desempeñar los puestos de trabajo de que se trate, ni tampoco permitir la continuidad en los puestos a los que no mantengan la declaración de aptitud en los posteriores reconocimientos médicos. No obstante, otro sector (Sala Franco, Arnau Navarro, 1996: 23; Fernández Villalón, 1997: 15; Purcalla Bonilla, 1997), tomando como base el art. 6.1 f) LPRL que alude a la fijación reglamentaria de "controles médicos especiales» para trabajos especialmente peligrosos, postulan la intervención reglamentaria en esta materia.

No obstante, también ha existido un importante contraste doctrinal de pareceres sobre la función de la negociación colectiva en este punto, admitiendo o rechazando que los convenios colectivos puedan añadir excepciones al principio general de voluntariedad de la vigilancia médica. $\mathrm{Al}$ respecto, nuestro alto tribunal ${ }^{15}$ y la doctrina judicial ${ }^{16}$ tienen declarado que la negociación colectiva no puede configurar como obligatorios reconocimientos que no lo son ex lege, ni siquiera dotarles de una caracterización contraria a las directrices de la ley, pues así se impone a tenor de la función de la negociación colectiva en materia de prevención de riesgos laborales. Ante el carácter de derecho necesario indisponible, se rechaza cualquier posibilidad de que a través de las cláusulas de los convenios colectivos se pretenda imponer la obligatoriedad para las personas trabajadoras de los reconocimientos médicos en supuestos distintos de los establecidos en las normas legales o reglamentarias; lo que no significa, sin embargo, que no pueda efectuarse mediante la negociación colectiva la identificación, concreción o delimitación de las situaciones o los puestos de trabajo que en el sector o empresa reúnan los requisitos fijados en la ley para hacer obligatorio el reconocimiento.

En este último caso, de momento, no existe ninguna disposición legal que obligue a realizar reconocimientos médicos para detectar posibles personas trabajadoras infectadas. Sólo se prevén las pruebas de PCR para cuando una persona presenta síntomas compatibles con el COVID-19, pero sin ser obligatorios.

\section{Covid-19 y reconocimientos médicos previos}

El reconocimiento médico previo a la contratación laboral plantea su problema cuando se utiliza como elemento de discriminación en la contratación y selección de personal.

Debe destacarse que los exámenes de salud previos a la incorporación al trabajo, como exigencia de cara a la contratación, venían regulados en instrumentos normativos previos a la LPRL. Así lo regulaba el art. 196 LGSS/1994 (hoy

\footnotetext{
15 STC 196/2004, de 15 de noviembre.

16 STSJ Madrid, de 29 de octubre de 2012, rec. núm. 33/2012.
} 
art. 243 LGSS/2015) para todos los puestos con riesgo de enfermedad profesional, en la regulación de determinadas actividades y en la normativa de menores y trabajadores del mar. Además, en algunos casos se reguló como requisito sine qua non para la contratación de la persona trabajadora.

No obstante, la LPRL no contiene referencia alguna a estos exámenes de salud previos. El art. 22 LPRL sólo se refiere a la vigilancia periódica de la salud, y el art. $7.3 \mathrm{~b}$ ) RSP prevé una evaluación de la salud de las personas trabajadoras inicial después de la incorporación al trabajo o después de la asignación de tareas específicas con nuevos riesgos para la salud. De ahí que se plantee si estos reconocimientos previos regulados con anterioridad a la normativa preventiva resultan compatibles y, por tanto, están vigentes, o si se oponen a la misma.

De cualquier forma, debe entenderse que dichos reconocimientos médicos previos no son incompatibles con la normativa de la LPRL, pues, debe recordarse que su no realización está penalizada tanto para la empresa infractora como por la entidad aseguradora de la contingencia.

En este sentido, puede plantearse la posibilidad de que se puedan realizar reconocimientos preventivos iniciales para detectar la inmunidad frente al COVID-19 como requisito selectivo para la contratación.

Para ello, debe indicarse que los reconocimientos previos a la contratación no encajan formalmente en los supuestos del art. 22 LPRL, ni en el art. 37 RSP, sino que cuando esta normativa se refiere a reconocimientos iniciales son «después de la incorporación al trabajo», porque el derecho-deber de prevención nace con la vigencia de la relación laboral (Gómez Caballero, 2005: 706).

No obstante, debe matizare, que los exámenes previos a la contratación, sí quedan regulados si los riesgos lo hacen necesario. El art. 243 LGSS los regula para ciertas actividades como requisitos obligatorios antes de la admisión al trabajo. Sin embargo, ello no permite admitir que desde un punto de vista preventivo deba entenderse que los exámenes previos puedan ser indiscriminados o generalizados, pues quedan vinculados a determinados riesgos o personas. Además, de lo contrario, conllevaría que la empresa pudiera controlar las aptitudes laborales de forma previa a la contratación sirviendo como medio de discriminación. De hecho, el TC ha señalado que el reconocimiento médico:

no es un instrumento del empresario para llevar un control dispositivo de la salud de las personas trabajadoras, como tampoco es una facultad que se le reconozca para verificar la capacidad profesional o la aptitud psicofísica de sus empleados con un propósito de selección de personal o similar (salvo que el tipo de trabajo a realizar lo justifique, cabría precisar) ${ }^{17}$.

17 STC 196/2004, de 15 de noviembre. 
Es decir, como se deduce de la doctrina constitucional, los reconocimientos médicos pueden ser utilizados por la empresa a efectos de contratación, pues no se puede justificar "para verificar la capacidad profesional o la aptitud psicofísica de sus empleados con un propósito de selección de personal o similar» ${ }^{18}$.

La lógica preventiva en los reconocimientos médicos previos a la contratación se recoge en algunos protocolos de vigilancia de la salud y son admitidos por los tribunales. Los protocolos previstos legalmente para determinados riesgos vinculan los reconocimientos previos a la ocupación de la persona trabajadora en puestos con determinados riesgos que exigen valorar la aptitud del trabajador, como los protocolos sobre riesgos derivados de radiaciones ionizantes o de trabajos en cajones de aire comprimido (Toscani Jiménez, 2007: 34).

Por su parte, la jurisprudencia ${ }^{19}$ ha valorado, en algunas ocasiones, la legalidad de estos reconocimientos previos a la contratación desde la óptica de la prevención, aplicando los criterios del art. 22 LPRL.

En relación con la obligatoriedad de estos reconocimientos médicos previos, cabe tener en cuenta, por un lado, su práctica extendida en los convenios colectivos, y que según el TC ${ }^{20}$ :

no puede configurar como obligatorios reconocimientos que no lo son ex lege, ni siquiera dotarles de una caracterización contraria a las directrices de la Ley, pues así se impone a tenor de la función de la negociación colectiva en materia de prevención de riesgos laborales (art. 2.2 LPRL) (...) reservándose a los convenios colectivos únicamente la función de mejora y desarrollo.

Lo único que está admitido es dar concreción a los supuestos excepcionales del art. 22.1 LPRL u otros casos previstos en la Ley o los reglamentos, como el art. 25 LPRL o 243 LGSS, debiendo adecuar a los criterios fijados por el TC, esto es, vinculación a riesgos, proporcionalidad e indispensabilidad.

Estas cláusulas pueden encontrar, en la práctica, una justificación genérica en sectores de la industria alimenticia, aunque cabe tener presente que no se pueden admitir en términos generales la legalidad de cláusulas en los convenios colectivos que establecen la obligatoriedad sin matices, imponiendo a las personas trabajadoras el deber de someterse, con carácter previo a su admisión, a un reconocimiento médico que determinará su aptitud para el trabajo, o incluso

18 STC 196/2004, de 15 de noviembre.

19 STS de 28 de diciembre de 2006, rec. núm. 140/2005, que valora la legalidad del reconocimiento médico previsto en una cláusula del convenio colectivo de Correos y Telégrafos y concluye que se trata de un reconocimiento de selección, no de prevención, pero cuya legalidad justifica por ser respetuoso del art. $22 \mathrm{LPRL}$.

20 STC 196/2004, de 15 de noviembre. 
cuando lo estime oportuno la empresa o ésta conjuntamente con los representantes de las personas trabajadoras.

Un sector judicial ${ }^{21}$ ha admitido la obligatoriedad en base a la acreditación de una justificación genérica, pero con acuerdo de los representantes o por el hecho de estar pactado en el convenio. Desde esa práctica, los informes de los representantes, que no son vinculantes según el art. 22 LPRL, resultan ser muy relevantes. Así se ha señalado que no puede admitirse una cláusula de reconocimiento médico obligatorio sin más justificación que la de venir pactada en convenio en base a que no existe un informe de los representantes avalando la obligatoriedad.

\section{Covid-19, derecho a la intimidad y protección de datos de la salud}

Es evidente que la información relativa al estado de salud de las personas forma parte de la intimidad. En este sentido, a pesar de que la legislación no ofrece criterios de referencia para determinar qué deba entenderse por información relativa a la salud, parece lógico considerar que son datos relativos a la salud todos aquellos relacionados con el estado físico o mental de una persona, comprendiendo aquí también cualquier otra información que tenga un vínculo con el estado de salud de esta persona, como la posibilidad de haber sido afectado por COVID-19.

Además, el TC señala que el derecho fundamental a la intimidad contempla el derecho a resguardar del conocimiento de terceras personas las informaciones íntimas, pero también y, especialmente, el derecho a controlar la circulación de las informaciones personales. Como señala el propio $\mathrm{TC}^{22}$, el derecho a la intimidad «garantiza el secreto de nuestra esfera de vida personal y, por tanto, veda que sean terceros, particulares o poderes públicos, quienes decidan cuáles son los contornos de nuestra vida privada». En este sentido, se afirma que se vulnera la intimidad no solamente cuando se vulnera la intimidad con la penetración en el ámbito propio y reservado del sujeto, sino también en aquellos casos en los que se produzca un quebranto de la "conexión entre información personal que se recaba y el objetivo para el que fue recogido». En definitiva, la tutela de la intimidad no depende tanto de la información conocida como de la capacidad del individuo de disponer de ella y, en particular, la capacidad de conocer y poder decidir acerca del destino de la información de los datos de carácter personal de la persona trabajadora.

La historia clínica es definida como el «conjunto de documentos que contienen los datos, valoraciones e informaciones de cualquier índole sobre la situa-

21 STSJ Asturias, de 9 de noviembre de 2007, rec. núm. 2651/2007.

22 STC 83/2002, de 22 de abril. 
ción y la evolución clínica de un paciente a lo largo del proceso asistencial» ${ }^{23}$. En la medida en que los datos relativos a la salud forman parte de la privacidad que garantiza el art. $18 \mathrm{CE}$, puede señalarse que existe un derecho a la confidencialidad de los datos clínicos, lo que supone que la revelación de dicha información sin autorización de la persona trabajadora estaría vulnerando el derecho fundamental a la intimidad del trabajador, así como también la dignidad humana (art. 10.1 CE).

El art. 5 LO 3/2018 ${ }^{24}$ reitera la obligación de confidencialidad que recae sobre los responsables y encargados del tratamiento de datos. En este sentido, el art. 9 Reglamento General de Protección de Datos (RGPD) ${ }^{25}$, al que se remite el art. 9 LO 3/2018 sólo permite el tratamiento sobre la salud cuando así lo exija la gestión de los sistemas y servicios de asistencia sanitaria y social. Asimismo, el art. 10.3 L 14/1986 26 y el art. 7.1 Ley 41/2002, reiteran el carácter confidencial de esta información.

En relación con el acceso por parte de la empresa y de quienes tienen competencias en materia de prevención, se declara la reserva de confidencialidad, por lo que no tienen acceso al conocimiento de las condiciones psico-físicas de la persona trabajadora. De hecho, el Convenio núm. 161 OIT $^{27}$, aunque aún está pendiente de ratificar por Espańa, señala en su art. 16 que:

al término de un examen médico prescrito para determinar la aptitud de un trabajador para un puesto de trabajo que entraña exposición a un riesgo determinado, el médico que lo haya realizado deberá comunicar sus conclusiones por escrito al trabajador y al empleador. Esta comunicación no debería contener indicación alguna de índole médica; según los casos, podrán indicar que el trabajador es apto para el puesto de trabajo previsto o bien especificar los tipos de trabajo y las condiciones de trabajo que le estén contraindicados, temporal o permanentemente desde el punto de vista médico.

De ahí que en relación con las prácticas empresariales que pretenden conocer los datos relativos a la salud, especialmente, en relación con haber sufrido el

23 Art. 3 Ley 41/2002. A mayor abundamiento, el art. 14 Ley 41/2002 indica que «la historia clínica comprende el conjunto de los documentos relativos a los procesos asistenciales de cada paciente, con la identificación de los médicos y de los demás profesionales que han intervenido en ellos, con objeto de obtener la máxima integración posible de la documentación clínica de cada paciente, al menos en el ámbito de cada centro. 2. Cada centro archivará las historias clínicas de sus pacientes, cualquiera que sea el soporte papel, audiovisual, informático o de otro tipo en el que consten, de manera que queden garantizadas su seguridad, su correcta conservación y la recuperación de la información».

${ }^{24}$ De 5 de diciembre, de Protección de Datos Personales y garantía de los derechos digitales.

25 Reglamento (UE) 2016/679, del Parlamento Europeo y del Consejo, de 27 de abril de 2016, relativo a la protección de las personas físicas en lo que respecta al tratamiento de datos personales y a la libre circulación de estos datos y por el que se deroga la Directiva 95/46/CE.

26 De 25 de abril, General de Sanidad.

27 De 25 de junio de 1985, sobre los servicios de salud en el trabajo. 
COVID-19, como requisito para poder ser contratado, la Agencia Española de Protección de Datos ha advertido que constituyen una vulneración de la normativa de protección de datos aplicable. Así, la citada Agencia ha indicado que, sobre la posibilidad de tratar los datos resultantes de la citada pandemia, con carácter general:

la normativa de protección de datos personales, en tanto que, dirigida a salvaguardar un derecho fundamental, se aplica en su integridad a la situación actual, dado que no existe razón alguna que determine la suspensión de derechos fundamentales, ni dicha medida ha sido adoptada ${ }^{28}$.

La información de haber padecido el coronavirus y desarrollado anticuerpos de esta enfermedad es un dato personal relativo a la salud, que el RGPD califica de categoría especial en su art. 9, por lo que su recogida y utilización por la posible empresa empleadora está sujeta a la normativa de protección de datos, fundamentalmente el citado RGPD y la LO 5/2018, que resultan plenamente aplicables.

\subsection{Consentimiento libre y expreso}

Para que el consentimiento sea válido debe consistir en una manifestación de voluntad libre, específica, informada e inequívoca. El RGPD ha dejado bien claro que el consentimiento no debe considerarse libremente prestado cuando no se goza de verdadera o libre elección o no puede denegar o retirar su consentimiento sin sufrir perjuicio alguno (considerando 42), o cuando exista un desequilibro claro entre las partes (considerando 43), como sucedería en el presente caso, en el que el consentimiento estaría condicionado por la necesidad o la voluntad de acceder a un puesto de trabajo, lo que anularía la libertad de la persona.

En ese sentido, el Comité Europeo de Protección de Datos ha ratificado las Directrices sobre el consentimiento en el sentido del Reglamento (UE) 2016/679, adoptadas el 28 de noviembre de 2017 por el Grupo de Trabajo del Artículo 29 y revisadas por última vez el 10 de abril de 2018 (WP259), que consideran que en el contexto del empleo se produce un desequilibrio de poder dada la dependencia que resulta de la relación entre las partes, y no es probable que la persona candidata pueda negar a la empresa el consentimiento para el tratamiento de datos sin experimentar temor o riesgo real de que su negativa produzca efectos perjudiciales; $y$, por tanto, considera problemático que la empresa realice el tratamiento de datos personales de empleados y empleadas actuales o futuros sobre la base del consentimiento, ya que no es probable que éste se otorgue libremente.

28 Informe de la Agencia Española de Protección de Datos 17/2020. Disponible en https:// www.aepd.es/es/documento/2020-0017.pdf 
La AEPD considera que no es tampoco aplicable el art. 6.1 b) RGPD, por cuanto la solicitud de dicho dato de salud no sería necesaria para la ejecución o formalización del contrato de trabajo y, por lo tanto, dicho tratamiento sería excesivo y contravendría el principio de minimización de datos fijado en el art. 5.1.c) RGPD.

En conclusión, solicitar información sobre el estado de inmunidad frente al COVID-19 iría más allá de las obligaciones y derechos específicos que impone a la empresa la legislación laboral y de la seguridad y protección social, en particular, del deber de proteger a las personas trabajadoras frente a los riesgos laborales previsto en la LPRL. En primer lugar, porque la persona interesada aún no es empleada y la empresa no tiene, por tanto, obligaciones o derechos específicos frente a ella. En segundo lugar, porque la información sobre una posible inmunidad frente a la enfermedad no contribuye significativamente a la protección del resto del personal o de la propia persona, en la medida en que los protocolos de prevención de riesgos adoptados por las autoridades sanitarias y laborales se aplican por igual a todo el personal, orientándose por lo que se refiere a la presencia de infección a los casos sospechosos. Estos protocolos no establecen excepción alguna para personas que ya hayan padecido la enfermedad. Finalmente, porque la misma consideración habría de atribuirse a la COVID-19 que a cualquier otro tipo de enfermedad que pudiera conllevar un riesgo de infección, sin que se plantee esta cuestión en la actualidad sobre otras enfermedades que pudieran resultar de declaración obligatoria a las autoridades sanitarias conforme al Real Decreto 2210/1995, de 28 de diciembre, por el que se crea la red nacional de vigilancia epidemiológica ${ }^{29}$.

\subsection{Tratamiento de datos}

Debe partirse del Considerando núm. 46 RGPD que reconoce que, en situaciones excepcionales, como una epidemia, la base jurídica de los tratamientos puede ser múltiple, basada tanto en el interés público, como en el interés vital del interesado u otra persona física. Literalmente, indica que:

el tratamiento de datos personales también debe considerarse lícito cuando sea necesario para proteger un interés esencial para la vida del interesado o la de otra persona física. En principio, los datos personales únicamente deben tratarse sobre la base del interés vital de otra persona física cuando el tratamiento no pueda basarse manifiestamente en una base jurídica diferente. Ciertos tipos de tratamiento pueden responder tanto a motivos importantes de interés público como a los intereses vitales del interesado, como por ejemplo cuando el tratamiento es necesario para fines humanitarios, incluido el control de epidemias y su propagación, o en situaciones de emergencia humanitaria, sobre todo en caso de catástrofes naturales o de origen humano.

29 Informe de la Agencia Española de Protección de Datos 17/2020. Disponible en https:// www.aepd.es/es/documento/2020-0017.pdf 
Por lo tanto, en base al RGPD, concretamente, su art. 6.1, se permite el tratamiento de datos por dos motivos, cuales son, por misión realizada en interés público (art. 6.1.e) o intereses vitales del interesado u otras personas físicas (art. 6.1.d).

El RGPD requiere para el tratamiento de datos personales la existencia de una fundamentación recogida en su art. 6.1, y cuando se traten categorías especiales de datos personales, como son los datos relativos a la salud, es necesaria también la concurrencia de una de las excepciones previstas en el art. 9.2 RGPD que permiten levantar la prohibición de su tratamiento.

Entre las bases jurídicas que en principio podrían fundamentar dicho tratamiento por la empresa estarían el consentimiento del interesado, conforme al art, 6.1.a) RGPD, o la prevista en su art. 6.1.b), relativa al tratamiento necesario para la ejecución de un contrato en el que la persona candidata es parte o para la aplicación a petición de esta de medidas precontractuales.

Es decir, según el citado informe de la AEPD las circunstancias que podrían dar lugar a dicho tratamiento pueden encontrarse en los siguientes apartados del art. 9.2 RGPD. En primer lugar, según el apartado b) del art. 9.2 RGPD, en las relaciones laborales entre empresa y persona trabajadora, por cuanto el tratamiento es necesario para el cumplimiento de obligaciones y el ejercicio de derechos específicos del responsable del tratamiento (la empresa) o del interesado en el ámbito del Derecho laboral y de la seguridad y protección social, ya que según el art. 14 LPRL, la empresa debe garantizar la seguridad y salud de todas las personas trabajadoras a su servicio. Asimismo, el art. 29 LPRL, recoge, como obligación de la persona trabajadora, que esta debe velar, según sus posibilidades y mediante el cumplimiento de las medidas de prevención que en cada caso sean adoptadas, por su propia seguridad y salud en el trabajo y por la de aquellas otras personas a las que pueda afectar su actividad profesional, a causa de sus actos y omisiones en el trabajo, de conformidad con su formación y las instrucciones de la empresa. También recoge la obligación de la persona trabajadora de informar de inmediato a su superior jerárquico directo, y a las personas trabajadoras designadas para realizar actividades de protección y de prevención o, en su caso, al servicio de prevención, acerca de cualquier situación que, a su juicio, entrañe, por motivos razonables, un riesgo para la seguridad y la salud de las personas trabajadoras. Por tanto, en el contexto de la situación derivada del COVID-19 supone que la persona trabajadora deberá informar a la empresa en caso de sospecha de contacto con el virus, a fin de salvaguardar, además de su propia salud, la de los demás trabajadores del centro de trabajo, para que se puedan adoptar las medidas oportunas. La empresa deberá tratar dichos datos conforme al RGPD, debiendo adoptarse las medidas oportunas de seguridad y responsabilidad proactiva que demanda el tratamiento (art. 32 RGPD). 
En segundo lugar, en los apartados g) e i) art. 9.2 RGPD se recoge el interés público, ya sea calificado como «esencial» o «en el ámbito de la salud pública, como la protección frente a amenazas transfronterizas graves para la salud».

En tercer lugar, el art. 9.2 h) RGPD, lo prevé para cuando el tratamiento es necesario para realizar un diagnóstico médico, o evaluación de la capacidad de laboral de la persona trabajadora o cualquier otro tipo de asistencia de tipo sanitario o para la gestión de los sistemas y servicios de asistencia sanitaria y social.

En cuarto lugar, también se permite el tratamiento de datos, según la letra c), cuando sea necesario para proteger intereses vitales del interesado o de otra persona física, en el supuesto de que el interesado no esté capacitado, física o jurídicamente, para dar su consentimiento.

De esta forma, en relación con la situación de crisis sanitaria por el COVID-19, y según la normativa de prevención de riesgos laborales la empresa puede tratar, de acuerdo con dicha normativa y con las garantías que estas normas establecen, los datos de su plantilla necesarios para garantizar la salud de todas las personas trabajadoras, lo que incluye igualmente al resto de empleados distintos del interesado, para asegurar su derecho a la protección de la salud y evitar contagios en el seno de la empresa y/o centros de trabajo.

En este sentido, el Comité Europeo de Protección de Datos, en declaración de 19 de marzo de 2020, ha señalado que la normativa de protección de datos no es un obstáculo para las medidas adoptadas en la lucha contra la pandemia. Considera que, en el ámbito laboral, el tratamiento de datos personales puede ser necesario para cumplir con una obligación legal a la que está sujeta la empresa, como es la obligación de garantizar la seguridad y salud laboral de las personas trabajadoras, así como el control de enfermedades y otras amenazas para la salud.

Ahora bien, los tratamientos de datos personales en estas situaciones de emergencia sanitaria, siguen siendo tratados de conformidad con el RGPD y LO 3/2018, por lo que se aplican todos sus principios, contenidos en el artículo 5 RGPD, y entre ellos el de tratamiento de los datos personales con licitud, lealtad y transparencia, así como el principio de exactitud y el de minimización de datos. Sobre este último aspecto hay que hacer referencia expresa a que los datos tratados habrán de ser exclusivamente los limitados a los necesarios para la finalidad pretendida, sin que se pueda extender dicho tratamiento a cualesquiera otros datos personales no estrictamente necesarios para dicha finalidad, sin que pueda confundirse conveniencia con necesidad, porque el derecho fundamental a la protección de datos sigue aplicándose con normalidad, sin perjuicio de que, como se ha dicho, la propia normativa de protección de datos personales establece que en situaciones de emergencia, para la protección de intereses esenciales de salud pública y/o vitales de las personas físicas, podrán tratarse los datos de salud necesarios para evitar la propagación de la enfermedad que ha causado 
la emergencia sanitaria. Todo tratamiento de datos debe cumplir con los principios establecidos en el art. 5 RGPD, en particular ser tratados de manera lícita y que su recogida obedezca a finalidades legítimas.

Por tanto, y, en resumen, según la AEPD, y así lo estimo yo, solicitar la empresa a las personas candidatas a un puesto de trabajo información sobre la inmunidad al COVID-19, como requisito para acceder a un puesto de trabajo, daría lugar a una diferencia de trato que no obedece a una justificación objetiva y razonable. Y ello viene recogido así en el RGPD, pues parte de que hay que proteger los derechos fundamentales y la dignidad de las personas en los tratamientos que se produzcan en el ámbito laboral, en particular, a efectos de contratación de personal, pudiendo los Estados miembros establecer disposiciones más específicas que las previstas para los tratamientos de datos personales con carácter general «para preservar la dignidad humana de los interesados así como sus intereses legítimos y sus derechos fundamentales, prestando especial atención a la transparencia del tratamiento...» (art. 88 y considerando 155 RGPD).

\subsection{Derecho a la intimidad}

No debe olvidarse la necesidad de respetar en todo momento el derecho a la intimidad de la persona trabajadora en la realización del reconocimiento médico, ya sea voluntario u obligatorio.

Este derecho, como es sabido por la extensa doctrina constitucional, «implica la existencia de un ámbito propio y reservado frente a la acción y el conocimiento de los demás» ${ }^{30}$.

La función del derecho a la intimidad, afirma el máximo intérprete de la Constitución, «es la de proteger frente a cualquier invasión que pueda realizarse en aquel ámbito de la vida personal y familiar que la persona desea excluir del conocimiento ajeno y de las intromisiones de terceros en contra de su voluntad», garantizando el «secreto sobre nuestra propia esfera de vida personal», confiriendo al individuo el poder jurídico de imponer a terceros «el deber de abstenerse de toda intromisión en la esfera íntima y la prohibición de hacer uso de lo así conocido», salvo que la intromisión esté fundada en una previsión legal que tenga «justificación constitucional y que sea proporcionada, o que exista un consentimiento eficaz que lo autorice, pues corresponde a cada persona acotar el ámbito de intimidad personal y familiar que reserva al conocimiento ajeno» ${ }^{31}$.

Para analizar la posible vulneración de este derecho se recurre al principio de proporcionalidad entre el fin pretendido con la medida empresarial y la restricción del derecho, a fin de determinar si existe o no vulneración del mismo, de-

30 STC 196/2004, de 15 de novembre.

31 SSTC 57/1994, de 28 de febrero; 143/1994, de 9 de mayo; 98/2000, de 10 de abril. 
terminando así si la medida es susceptible de conseguir el objeto propuesto (juicio de idoneidad), si es necesaria en el sentido de que no exista otra medida más moderada para la consecución de tal propósito con igual eficacia (juicio de necesidad) y si la misma es ponderada o equilibrada, por derivarse de ella más beneficios o ventajas para el interés general que perjuicios sobre otros bienes o deberes en conflicto (juicio de proporcionalidad en sentido estricto) ${ }^{32}$.

De ahí, la necesidad de informarse a la persona trabajadora con carácter previo a la realización de las pruebas que conforman el reconocimiento médico de cuáles son dichas pruebas a realizar, así como la finalidad de cada una de ellas ${ }^{33}$.

\section{Conclusiones}

En el momento actual que estamos atravesando de crisis sanitaria ocasionada por la pandemia de COVID-19, no cabe duda que debe protegerse en primer lugar la salud, pero ello no puede suponer tampoco la vulneración de otros derechos fundamentales como a la intimidad, o protección de datos de carácter personal sin más.

Por un lado, en relación a la obligatoriedad del reconocimiento médico, en mi opinión, es en la segunda excepción donde queda encuadrada, pues una de las medidas que la empresa puede adoptar para evitar la propagación del virus entre su plantilla se encuentra en la realización de dichos reconocimientos médicos. Como señala nuestro alto tribunal:

el derecho del trabajador a preservar su intimidad personal cede así ante el derecho a la salud del resto de trabajadores que puedan verse afectados por el estado patológico de un compańero y el del empresario a conocer la existencia de enfermedades capaces de originar riesgos ańadidos al puesto de trabajo y situaciones de peligro para cuantos se relacionan con el trabajador enfermo, circunstancia en virtud de la cual se establecen tres excepciones ${ }^{34}$.

Es decir, la realización de dichos reconocimientos con carácter obligatorio a las personas trabajadoras con el fin de detectar la presencia del SARS-CoV-2 queda justificada. Ello, no obstante, no supone, en ningún caso, que no se tengan que respetar los requisitos y límites que establece el art. 22 LPRL.

Por otro lado, sobre la garantía de protección de los derechos de carácter personal, el Comité Europeo de Protección de Datos manifiesta que la norma-

\footnotetext{
32 STSJ Navarra, de 14 de enero de 2008, rec. núm. 350/2007.

33 STC 196/2004, de 15 de novembre.

34 STS de 10 de junio de 2015, rec. núm. 178/2014.
} 
tiva de protección de datos no impide tomar medidas en la lucha contra la pandemia, pero advierte también de que en estas situaciones excepcionales debe garantizarse una especial protección en dichos datos personales. Es decir, deberán respetarse siempre los principios del art. 5 RGPD.

El tratamiento de datos de salud de la persona trabajadora con el objeto de frenar la expansión el SARS-CoV-2 queda justificado en aplicación del art. 9.1 RGPD, pues viene ligado a la necesidad de proteger la salud pública y general.

La normativa de protección de datos se aplica en su integridad a la situación actual, pues no existe razón alguna que determine que los derechos fundamentales implicados quedan suspendidos. Ello significa que las empresas deberán garantizar la confidencialidad, integridad y disponibilidad de los datos de los que sean responsables, pudiendo tratar los datos de sus personas trabajadoras, y de sus visitantes o clientes, incluidos sus datos de salud, y adoptar las medidas que consideren convenientes para garantizar la salud de su plantilla (Muñiz Aguirreurreta, 2020).

En definitiva, en la situación de pandemia en la que nos encontramos, que tiene, entre sus objetivos prioritarios, frenar la expansión del virus, el interés de protección de la salud pública cobra un especial relieve, por encima, en cierta forma, de muchos derechos de los ciudadanos, como el derecho a la intimidad o el derecho a la protección de datos de carácter personal. Ni el derecho a la intimidad, ni ningún otro concede unos poderes ilimitados, en la medida en que todos deben ceder ante determinados derechos constitucionales, siempre que el recorte sea necesario para lograr el fin legítimo previsto, sea proporcionado, y respetuoso con el contenido esencial del derecho.

\section{Bibliografía}

Beltrán de Heredia Ruiz, Ignasi (2020) «COVID-19 y reconocimiento médico de los trabajadores» [blog] Una mirada critica a las relaciones laborales. Disponible en https://ignasibeltran.com/2020/04/15/covid-19-y-reconocimiento-medico-de-los-trabajadores/

Blasco Pellicer, Ángel (1999) «El deber empresarial de vigilancia de la salud y el derecho a la intimidad del trabajador», en AA.VV., Trabajo y libertades públicas. Madrid: La Ley.

Cavas Martínez, Faustino (2004) «Vigilancia de la salud y tutela de la intimidad del trabajador. A propósito de la Sentencia del TC 196/2004, de 15 de noviembre», $A S$, núm. 19.

Fernández Villalón, Luis Antonio (1997) «Vigilancia de la salud y derechos de la persona del trabajador (comentarios al art. 22 de la Ley de prevención de riesgos laborales)», REDT, núm. 82.

García Blasco, José, González Labrada, Manuel (1998) «La salud de los trabajadores», en AA.VV., Derecho de la Seguridad y Salud en el Trabajo. Madrid: Civitas. 
García-Perrote Escartín, Ignacio; Mercader Uguina, Jesús (2017) «Los reconocimientos médicos obligatorios en la doctrina reciente de los tribunales», $R I L$, núm. 5 (versión on line).

Gómez Caballero, Pedro (2005) «Vigilancia y control del estado de salud y respeto al derecho a la intimidad del trabajador", $R L$, Tomo II.

González Ortega, Santiago; Aparicio Tovar, Joaquín (1996) Comentarios a la Ley 31/1995, de Prevención de Riesgos Laborales. Madrid: Trotta.

GoŃ I SeIn, José Luís (1999) «Límites constitucionales a los reconocimientos médicos obligatorios establecidos como medida de prevención de riesgos laborales», $R D S$, núm. 5 .

López Ahumada, José Eduardo (2020) «El control empresarial de la temperatura corporal de los trabajadores ante la vicisitud del Covid-19», Diario La Ley, núm. 5.

Lousada Arochena, José Fernando (1997) «La vigilancia de la salud laboral de los trabajadores», Poder Judicial, núm. 48.

Marín Malo, Mirentxu (2020) «La realización de reconocimientos médicos para la detección de Covid-19 a los trabajadores", Lan Harremanak, núm. 43.

Martínez Fons, Daniel (2002) La vigilancia de la salud de los trabajadores en la Ley de Prevención de Riesgos Laborales. Valencia: Tirant Lo Blanch, (versión on line)

Ministerio de SANidAd (2020) Instrucciones sobre la realización de pruebas diagnosticas para la detección del COVID-19 en el ámbito de las empresas. Madrid: Ministerio de Sanidad. Disponible en https://www.mscbs.gob.es/profesionales/saludPublica/ccayes/ alertasActual/nCov/documentos/instruccionesPruebasDiagnosticasEmpresas.pdf

Muñiz Aguirreurreta, David (2020) «COVID-19. Relaciones laborales y protección de datos», Aranzadi Digital, núm. 1.

Purcalla Bonilla, Miguel Ángel (1997) «Vigilancia de la salud de los trabajadores: claves interpretativas de su régimen jurídico" $A S$, Vol. V.

Ribas, Xavier (2020) «Control de la temperatura del trabajador: opinión sobre el comunicado de la AEPD», Aranzadi Digital, núm. 1.

Sala Franco, Tomás; Arnau Navarro, Francisco (1996) Comentarios a la Ley de Prevención de Riesgos Laborales. Valencia: Tirant lo Blanch.

TosCani JiméneZ, Daniel (2007) «Los reconocimientos médicos: su obligatoriedad y sus consecuencias», Gestión Práctica de Riesgos Laborales, núm. 29. 